\title{
Fatores de risco e medidas preventivas para quedas em idosos em ambiente domiciliar
}

\author{
Andresa Alzira de Souza Neto, Bianca Violeta Frade Barbosa, Karina Oliveira Martinho
}

\section{Resumo}

O processo natural do envelhecimento é caracterizado por alterações fisiológicas, principalmente nos sistemas visual, vestibular, cardiovascular, neurológico e osteomioarticular, o que limita a capacidade funcional do indivíduo, e favorece assim o risco de quedas, que por sua vez levam a consequências psicológicas e/ou físicas, o que pode torná-lo dependente ou até mesmo levá-lo a óbito. Associado a este quadro há consequências econômicas, que geram grandes gastos públicos diretos e indiretos. Este estudo teve por objetivo identificar no ambiente domiciliar do idoso os fatores de risco que favorecem as quedas. O estudo foi composto por 15 idosas participantes do Grupo da Terceira Idade da cidade de Santo Antônio do Grama - MG, com idade média de 72,93 anos. A coleta de dados foi num único encontro, onde houve a aplicação de um questionário sociodemográfico e do estado de saúde, seguido da Escala Ambiental de Risco de Quedas. A prevalência de quedas no último ano foi de $26,67 \%$, onde foram associadas à diminuição da acuidade visual e o uso de medicamentos hipotensores. Os fatores de risco encontrados na Escala Ambiental de Risco de Quedas foram a ausência de revestimentos uniformes e escadas com corrimãos inadequados. Tendo em vista que esses fatores de risco domiciliares identificados são modificáveis, torna-se necessário a orientação e implementação de medidas preventivas ao risco de quedas.

Descritores: Envelhecimento; Queda; Fatores de riscos ambientais 